\title{
Age Effects in Foreign Language Learning for Children in China
}

\author{
Zhiliang Liu \\ Department of Foreign Languages \\ Beihai College of Beijing Aeronautics and Astronautics University \\ No 88 Silver Beach Boulevard, Beihai 536000, China \\ Tel: 86-779-8627-868 E-mail: zlliuman@yahoo.com.cn \\ Guanying Chen \\ Foreign Languages Institute \\ Northwest Normal University \\ Lanzhou 730070, China
}

The research is financed by the National Basic Foreign Language Teaching Research Center of China. No. JJWYYB2006114

\begin{abstract}
To know the age effects in foreign language learning for children in China, we made both qualitative survey on the English teachers, the students and their parents by means of questionnaire; and quantitative survey on the students' scores from junior 1 to senior 2 ( 5 years) in the secondary school by analyses between those (over 30 students) who had learned English for 3 years in the elementary school and those (over 400 students) who hadn't. Finally conclusions that “"the younger, the better' in FLL is doubted, FLES shouldn't be done in lower grades of elementary school in China, qualified English teacher is the decisive factor on FLES" were drawn from the surveys on FLES in China.
\end{abstract}

Keywords: FLES, Age \& FLL, English teacher

\section{Introduction}

English has been taught in more and more elementary schools since the early 1990s, but offering English course in China is no easy task. The Chinese Ministry of Education made the decision of offering English course from grade 3 above county-level elementary schools in the fall of 2001, while that from grade 1 above township-level ones in the fall of 2002. This decision aroused debates among scholars in foreign language teaching and research nationwide. Some agreed to it, some disagreed, and some had an attitude of eclecticism by solving problems in the process of teaching.

In response, I made a survey on FLES (Foreign Languages in Elementary Schools) of over 30 pupils, starting English learning from grade 4 for 3 years in the Second Elementary School of Qinghai Oil Field in China. The survey was on their English scores from junior 1 to senior 2 in the secondary school, together with the attitudes on FLES from the students, their parents and their English teachers, both in elementary and secondary schools, by questionnaire. The aim is to draw some conclusions by analyzing the facts and figures collected and to test the previous studies in this field.

\section{Three viewpoints on FLES in China}

First: Many scholars say it's unnecessary to offer foreign language courses to children nationwide in a rigid and uniform manner without enough qualified teachers, suitable textbooks and other teaching equipment. They disagree to the idea "the younger, the better" in FLL (foreign language learning). The well-known professor Xu Guozhang, Gui Shichun, Zhang Zhengdong are among them.

Second: Among scholars in favor of the decision, professor Chen Lin is the chief representative. The ideas are based mainly on the conditions that there are qualified English teachers, suitable textbooks and good teaching equipment.

Third: Some scholars keep an attitude of eclecticism, whose viewpoint is solving the problems in the process of teaching and, professor Hu Zhuanglin is the main advocator. He suggested, no matter what kind of difficulties lying in 
front of us, we should offer the courses firstly in the places well-equipped, while the backward areas should do their best to catch up with the former gradually because we can't wait for better conditions.

Concerning the problem of starting age in FLL, there's been no agreement in the past 50 years in the world. Therefore, we should make people know that FLES has a very difficult situation worldwide. From the brief history of FLES in China, we are now repeating the same lesson taught in 1980s, especially in the backward areas, because of the same reason that lacks in qualified English teachers and the like. There are three kinds of viewpoints on FLES in China, but they agree on one point that qualified English teachers, suitable textbooks and adequate teaching equipment are the prerequisites in carrying out the decision, which are in great need in China now. 0

\section{FLES in China and its language environment}

Many people think child's age in FLL is: "the younger, the better". In my understanding, there must be some special language environment. As is known, it's quite different for Chinese children and American minorities' to learn English. For example, if a Chinese couple moves to the USA, their children will have to learn English in school as the Americans do. These Chinese children have to face the natural language environment and culture of English and have enough chances to communicate with the people around them. Although English isn't their mother tongue, the Chinese children have to face everything encoded by it. Thus, they can think, speak and develop naturally in English. The natural language environment of English would assure them to master English naturally. But in China, children can't have such an environment, and there's no natural communication in English for them. Therefore, their only way is to listen more, speak more, and practise more, to recite new words, language structures and grammar rules in learning English. This means the children's English in China is not natural or real English, but the transition of understanding Chinese and knowing English. It's a mixture of comparison from the two languages.

Obviously, it's natural for Chinese children to learn English well as an L2 (second language) in the USA, and "the younger, the better". But in China English is a foreign language, so it's a different matter, and "the younger in age, the more difficult in learning". Therefore, it is evident that there's no "critical period" in TEFL (teaching English as a foreign language) for children in China. "Critical period hypothesis" only exists in natural language (mother tongue and L2) acquisition as E.Lenneberg raised it in 1967. But it doesn't mean children can't learn foreign languages. What we should do is to create a suitable bilingual environment, compile good textbooks, use proper teaching methods according to children's psychology and physiology, but above all, it's to train qualified foreign language teachers.

\section{Analyses on the Results}

The comments and views of the students, the parents and the teachers are originals from the answers to the questionnaires.

\subsection{Analyses on the results of the questionnaires}

4.1.1 Students' personal experience and views on FLES (from open questions No.18 and 19)

\subsubsection{Personal experience}

Reasons for "like"

* To speak English freely in class made the class atmosphere lively and active.

* It's very interesting to have English names and we feel fresh and different from other schoolmates. It made us feel a sense of achievement, curiosity and superiority to have an English dialogue in front of the classmates, to learn to sing English songs everyday and to learn a new language and its culture compared with our schoolmates who didn't do it.

* Fewer texts and lively teaching in English class made us remember the things learned easily.

Reasons for "dislike"

* We couldn't have English classes regularly as the other subjects for the absence of the English teacher sometimes, so we forgot what we've learned easily.

* Compared with maths and Chinese, it's a bit interesting and easy, but it's rather confusing. Sometimes we were confused with the English letters and Chinese pinyin.

* We paid less attention to English just because our school paid less to it and it's not one of the major subjects. I just don't like it at all without any obvious reasons, nor to learn new words by heart. Not knowing much of English, I've no special feelings of it.

\subsubsection{Views}

Positive:

* We got the sense of superiority and it's helpful to learn English in junior secondary school. It enriched us with new contents and we gained some western culture. 
* Having developed interest in English earlier, it made me understand our English teacher better in junior secondary school. It made me one of the most successful students during my first two years of junior secondary school studies.

* The lively atmosphere in English class was the typical style of combining education with recreation, adding many colors and joys to the dull study life in elementary school. In the process of learning, English words were almost permeated in the games, benefiting a lot in developing interest in FLL.

Negative:

* Two English classes per week were fewer than expected. English teacher should be energetic to join in class activities to arouse pupils' interest and attentive to the demands of pupils and check their English timely. It's not helpful for English learning in junior secondary school because it's a bit confusing and unsystematic when putting English letters and Chinese pinyin together, so it's better to start English courses from junior secondary school.

* It's easier for those who had learned English when starting it again at the beginning of junior secondary school, but it made them stay behind for their pride and sense of superiority as time went on, therefore disadvantages outweighed advantages on FLES.

From Table 1 we know the students' sense of superiority in FLL over those who hadn't learned English in elementary school lasts one year on average in junior secondary school. In question No.7, the 'positive effect' is chosen by 26 students, while the 'negative effect' by 0 and other choices by 6 . On this point, whether the students or their parents (from the next questionnaire table), both of them agree to it, which is identical with the idea of most people in China for earlier start in FLL. From the personal experience, we know 23 students (71.88\%) like FLES, while 9 (28.13\%) dislike it. So we see most students like English, emphasizing much on the positive effect of fresh, interesting and active class atmosphere.

As to the open questions on FLES, we've got both positive (14 pieces) and negative (9 pieces) comments. In the pupils' opinion, it's helpful in FLL whether for laying a solid foundation for their junior secondary school English or for broadening their horizons. However, some say teaching method should still be improved, more classes be added, while some think it better to start it from junior secondary school because it brings pride and sense of superiority to the students, which makes them stay behind in FLL in secondary school.

From the above, we see most pupils like FLES, and they want to get some improvement from teachers in FLL, though FLES will bring them negative effect to later FLL because of their pride and sense of superiority.

4.1.2 Parents' comments and views on FLES (from open questions No.8, 13, 15 and 19)

\subsubsection{Comments}

Most parents consider FLES positively. Children have mastered some knowledge by learning English and their interest has been developed in playing games, learning English expressions and songs. Having made a solid foundation for their English learning, the children are doing it in a relaxed environment from the beginning to the end, so it's better for them to learn it from an earlier age. While a few think it a kind of load, therefore they are not sure whether to say it positive or negative. As to optimal age in FLL, the ages are from 5 to 11, but most regard the ages from 9 to 10 , which are in accordance with their choice of grade 3 on FLES, occupying 53.13\%.

\subsubsection{Views}

Positive:

* We feel happy about it. However, language environment is very important in FLL.

* Learning new words and expressions is not the only task for pupils, interest should be put to the first place, and try to avoid too much emphasis on oral English

* Textbooks should be connected with those in junior secondary school, but teacher is the most important among all, especially his pronunciation. A responsible teacher is of vital importance and the assessment of the pupils' examination is also the important direction in learning English.

* English should be taught but not at a lower grade. It is suitable to begin it from grade 5.

* It is good to do so but attention should be paid to teaching method. It should be supported and taken as a formal course like maths and Chinese. The sense of language is very important and the earlier learning will lay a solid foundation for children' English and it's very helpful.

* Class periods are fewer than expected. There should be one period each day. Oral English is of first importance. Activities should be added out of class and some homework also should be assigned. It is good but we worry that it might bring a heavy load to the pupils as a result.

Negative:

* It's not formal and our child's interest of English is ruined. 
* Generally speaking, it is good, but the problem is: what are the purpose and function of it?

From Table 2, 30 parents are in favor of FLES, occupying 93.75\%. Positive outweighing negative effect is the opinion of most parents from the answers to questions No.3, 4, 5, 6 and 7. In question No.9, 12 parents choose "pronunciation" while 14 choose "grammar" as the most difficult problem. When asked which grade is suitable for starting FLES, 11 parents choose grade 1, 17 select grade 3, 3 think it from kindergarten. 23 parents consider English teacher as the vital factor, covering 71.88\%. 25 parents (78.13\%) think "pronunciation" is the most important for children. And they think starting age of FLL is between 9 and 10, which is identical with the idea of many scholars. 20 parents $(62.50 \%)$ agree it's easier and more relaxed for kids to begin FLL in junior secondary school compared with those who hadn't learned it, so it's of positive effect, but saying this effect doesn't last for long, 5 students last for over 2 years, 8 for 1 or 2 years, 8 for 1 year and 11 for a few months.

From the views, most parents are in favor of FLES. Interest is mentioned most followed by pronunciation and oral English. They expect a solid foundation will be laid for children's English but worry their kids might be loaded with too much at the same time.

4.1.3 Teachers' comments and views on FLES (from open questions No.1, 3, 5, 9, 10, 12, 14, 16, 18, 31, 33, 35, 37, 38, 39 and 40)

\subsubsection{Comments}

Most teachers consider grade 3 (from 8 to 9 year-old) as the best choice and the most suitable ages to start FLL. The reasons are the pupils of grade 1 and 2 have already had the experience of learning Chinese pinyin at least for one year, so the possibility of confusion between English letters and Chinese pinyin gradually becomes less. Besides, the pupils of grade 3 have higher ability in expressing themselves and in absorbing knowledge than those of grade 1 and 2 . They agree on one point that adequate English teachers, suitable textbooks, necessary teaching equipment are the most important factors on FLES. This is identical with the suggestions by many scholars in China.

\subsubsection{Views}

Positive:

* Interest is the key in elementary school teaching, while lecturing and explanation is the main style in secondary school; spoken English is emphasized in elementary school teaching, while written work in secondary school.

* Those having learned English in advance have a larger vocabulary and better spoken English, which gives them advantages in FLL when starting to learn it again in junior secondary school, while those not having learned have some difficulty in English studies at the beginning.

* Those do better in English written work can have better in oral English naturally. Obviously oral and written English are complementary to each other.

* As to the questions No. 34 and 35, most consider "the ability of spoken English" more important than "the scores of English examination".

* The way of combining the English education with recreation should be penetrated through the whole teaching process, thus the pupils could learn English easily and quickly in relaxed ways.

* It's possible to offer English courses in elementary school due to the younger ages in absorbing languages easily. It's best to start FLES from grade 3 for having learned Chinese for two years.

* Much attention should be paid to FLES, but the most important is to have adequate teachers, suitable books and reasonable teaching arrangements besides the necessary English materials such as reference books, teaching cards and pictures.

Negative:

* I just don't agree to the policy of offering English courses in elementary school, which is due to the lack of English teachers, inadequate facilities at present, besides the confusion between English letters, English phonetic symbols and Chinese pinyin (altogether 130) for pupils in elementary school.

In sum, we see most of the English teachers support the policy of offering English courses in elementary school from grade 3 with the prerequisites that teachers, textbooks and teaching facilities should be adequate and suitable. When teaching in class, interest should be put in the first place besides the emphasis on oral English, the assessment of academic achievement, small class teaching and the like.

\subsection{Analyses of the students'scores}

4.2.1 Average scores of the students in junior 1-3 and senior 1-2

Analyses on the average scores of the students in junior 1-3: 
It's obvious the final average score of the 46 students is $3.21(117.43-114.22=3.21)$ points higher than that of the 390 students. The most obvious pair of scores is 139.7 to 130.49 in Junior1A, whose difference is over 9 points. This sum of scores indicates that the students who had learned English for 3 years in elementary school have more advantages than those who hadn't in learning English from junior one to three.

Analyses on the average scores of the students in senior 1-2:

It's evident the final average score of the 33 students is $1.97(78.93-76.96=1.97)$ points lower than that of the 448 students. The result is just upside-down compared with that of the junior students except for the scores of Senior2B. The most obvious pair of scores is 70.87 to 66.44 in Senior1A, whose difference is over 4 points. This sum of scores indicates that advantages are disappearing gradually as time goes on for those who had learned English for 3 years, finally disadvantages appear. It's clear the idea "the younger, the better" for children in FLL is doubted.

In sum, from Table 4, Table 5 and Figure 1, we see the students who had learned English in elementary school are superior to those who hadn't from their English exam results in junior secondary school, but gradually they are inferior to those who hadn't after getting into senior secondary school. This indicates the earlier beginner in FLL has less and less advantage as time goes on. In other words, the higher grade, the lower score is for those who had learned English for 3 years in elementary school when beginning to learn English from secondary school. This is in accordance with the theory of 'non-critical period' hypothesis raised by Snow in 1978. Therefore, the notion "the younger, the better" in FLL is doubted.

\subsubsection{Descriptive statistics of the scores}

Table 6 describes the general distributive tendency of the scores of junior 1-3 \& senior 1-2. The four categories are of the two groups of students: those who had learned English in elementary school for 3 years (Jr. Av. 46Ss. \& Sr. Av.33Ss.) and those who hadn't (Jr. Av. 390Ss. \& Sr. Av. 448Ss.). Among them there are 11 kinds of statistical data described. It's clear that the mean of the 46 students in junior and 33 in senior secondary school falls from the highest (mean=117.4286) to the lowest (mean=76.9550) in the four groups, while the mean of those 390 students in junior and 448 in senior secondary school rises from a lower one (114.2200) compared with 117.4286 to a higher one (mean=78.9275) compared with 76.9550. It's a sharp contrast compared with each other, between those who had learned English earlier and those who hadn't. This brings us the findings that the idea "the younger, the better" is doubted in FLL, which is in accordance with the findings in the previous analyses. The values of Standard Deviation show that the smallest differences (Std. V. $=6.71750$ ) can be found in the group of SR.Av.448Ss. While the biggest differences (Std.V. $=16.96582$ ) can be identified in the group of Jr.Av. 46Ss, it is more convincing to show the correctness and validity of the rational analyses in the previous findings. The rest of the descriptive statistics support the previous findings, too.

\subsubsection{Paired samples test on the scores of junior 1-3 and senior 1-2}

In this section the previous descriptive statistics of the scores will be tested by the paired samples $\mathrm{T}$ test with the help of SPSS 11.0 (Statistical Package for the Social Sciences) to see whether the findings are right or wrong.

In Table 7, it is obvious that all the figures are identical with those in Table 6. Hence, we know the statistics are proved to be true.

From Table 8, we see the correlation coefficients $(r=0.977 ; \mathrm{r}=0.935)$ and the figures of significant degree $(\mathrm{p}=0 ; \mathrm{p}=0.065)$ tally with those in Table 6 and Table 7 totally. So they are of high validity and correctness proved by the figures in the chart of the paired samples correlations.

From Pair 1 in Table 9, we see the figures: $\mathrm{t}=-1.816, \mathrm{df}=6$, so we check $\mathrm{t}$ value in the distribution table and find $\mathrm{t}=$ 3.707 at the level of $\mathrm{a}=0.01$ (in 2-tailed). It's clear that -1.816 is smaller than $3.707(-1.816<3.707)$, so we should accept the hypothesis of the correlation coefficient as 0 and consider that there is no correlation between the two variables. In other words, there are no significant differences between the scores of the 46 students and those of the 380 . Moreover, $\mathrm{p}=0.119$, and $0.119>0.01$ (in 2-tailed), so it can be regarded that there are no significant differences between the two variables, too.

While in Pair 2, it is clear that $\mathrm{t}=1.395, \mathrm{df}=3$, so we check $\mathrm{t}$ value in the distribution table and find $\mathrm{t}=5.841$ at the level of a $=0.01$ (in 2-tailed). It's clear that $1.395<5.841$, so we should accept the hypothesis of the correlation coefficient as 0 and consider that there is no correlation between the two variables. In other words, there are no significant differences between the scores of the 33 students and those of the 448. Moreover, $p=0.257$, and $0.257>0.01$ (in 2-tailed), therefore, it also can be considered that there are no significant differences between the two variables. As to the rest of the statistical data, there is no need to analyze them for their supporting evidence and validity.

From the findings in Table 9 and the explanations, we know there are no significant differences between the students' English scores of those who had learned English for 3 years in elementary school and those who hadn't both in junior and senior secondary schools. Therefore, there is no significant correlation between age and the English scores. From 
this T Test we can say the notion "the younger, the better" in FLL for children is doubted.

\section{Conclusion}

\subsection{FLES shouldn't be done in lower grades of elementary school in China.}

There is confusion among 26 English letters, 48 English phonetic symbols and 56 Chinese pinyin (altogether 130) for pupils in the beginning years in elementary school. The lower grades are the stage for pupils to lay a good foundation of their mother tongue. From the results of the questionnaires, most of the English teachers, the students, and the parents agree that children should begin FLL around the ages from 9 to 10, that is, from grade 3 in elementary school, which is identical with the idea of many scholars'.

\subsection{Qualified English teacher is the decisive factor on FLES.}

The important factors in FLL are qualified teachers, painstakingly designed courses, favorable language environment and the like. Moreover, interest and good learning habits are also among them. But qualified teacher is the decisive factor and this is what we need most at present. $40 \%$ to $50 \%$ of English teachers in elementary schools are not English majors in China in 2007 according to the figures by the Chinese Ministry of Education. If we let unqualified teachers go to the posts, the result will be from bad to worse. Under the present unfavorable situation of the teaching system in China, the more strictly we abide by the decision of FLES, the more traps will be appearing in front of foreign language learners. This will lead to even greater losses in terms of inaccurate teaching and wasted resources. These losses will be irreparable. Facing such unfavorable realities, we should be circumspect in implementing FLES, especially in the backward areas in China at present. And this is in accordance with the research done previously in some other countries in 1970s.

\subsection{The notion "the younger, the better" in FLL is doubted.}

The scores of those who had learned English for 3 years in elementary school were higher than those who hadn't when starting to learn English in junior secondary school, but from senior elementary school their scores were decreasing semester by semester compared with those who hadn't, finally their advantages disappeared completely. From the findings in Table 9, we know there are no significant differences between the students' English scores of those who had learned English for 3 years in elementary school and those who hadn't both in junior and senior secondary schools. Therefore, there is no significant correlation between the starting age and the English learning result. From the result of the T Test we can say the notion "the younger, the better" in FLL for children is doubted. Therefore there is no "critical period" hypothesis in FLL, it may only exist in natural language learning as E. Lenneberg put it forward in 1967.

In sum, all the above results showed that the starting age in FLL isn't “the younger, the better". H. Stern's (1999, p.367) view that "a language can be taught from any age upwards" was proved to be true again in China.

\section{References}

Ellis, R. (1999). The Study of Second Language Acquisition. Shanghai: Shanghai Foreign Language Education Press. p.692-712.

Krashen, S. et al. (Eds.). (1982). Child-adult Difference in Second Language Acquisition. Rowley Mass: Newbury House. p.11-16.

Lenneberg, E. (1982). Biological Foundation of Language. New York: Wiley. p.66-68.

Nikolov, M. (2000). Issues in Research into Early Foreign Language Programs. In Moon, J. \& Nikolov, M. (Eds.). Research into Teaching English to Young Learners: International Perspectives. University of Pécs, p.21-48.

Shichun Gui. (1992). Doubt on Foreign Language Learning Must Be Started from an Earlier Age. Foreign Language Teaching and Research. Issue 4. p.52-54.

Stern, H. (1999). Fundamental Concepts of Language Teaching. Shanghai: Shanghai Foreign Language Education Press. p.9-11, p.360-370. 
Table 1. Statistics of the views on FLES by the 32 students (17 closed questions)

\begin{tabular}{|c|c|c|c|c|c|c|c|c|}
\hline Number & A & Percent & B & Percent & C & Percent & D & Percent \\
\hline 1 & 32 & $100 \%$ & 2 & $6.25 \%$ & 7 & $21.88 \%$ & 0 & $0 \%$ \\
\hline 2 & 30 & $93.75 \%$ & 0 & $0 \%$ & 2 & $6.25 \%$ & 0 & $0 \%$ \\
\hline 3 & 3 & $9.38 \%$ & 20 & $62.50 \%$ & 9 & $28.13 \%$ & 0 & $0 \%$ \\
\hline s4 & 9 & $28.13 \%$ & 18 & $56.25 \%$ & 4 & 12.505 & 1 & $3.13 \%$ \\
\hline 5 & 6 & $18.75 \%$ & 1 & $3.13 \%$ & 25 & $78.13 \%$ & 0 & $0 \%$ \\
\hline 6 & 4 & $12.50 \%$ & 11 & $34.38 \%$ & 17 & $53.13 \%$ & 0 & $0 \%$ \\
\hline 7 & 26 & $81.25 \%$ & 0 & $0 \%$ & 6 & 18.755 & 0 & $0 \%$ \\
\hline 8 & 15 & $46.88 \%$ & 6 & $18.75 \%$ & 3 & $9.38 \%$ & 12 & $37.50 \%$ \\
\hline 9 & 20 & $62.50 \%$ & 9 & $28.13 \%$ & 0 & $0 \%$ & 3 & $9.38 \%$ \\
\hline 10 & 9 & $28.13 \%$ & 17 & $53.13 \%$ & 2 & $6.25 \%$ & 4 & $12.50 \%$ \\
\hline 11 & 28 & $87.50 \%$ & 4 & $12.50 \%$ & 0 & $0 \%$ & 0 & $0 \%$ \\
\hline 12 & 15 & $46.88 \%$ & 8 & $25.00 \%$ & 9 & $28.13 \%$ & 0 & $0 \%$ \\
\hline 13 & 22 & $68.75 \%$ & 6 & $18.75 \%$ & 5 & $15.63 \%$ & 0 & $0 \%$ \\
\hline 14 & 9 & $28.13 \%$ & 15 & $46.88 \%$ & 8 & $25.00 \%$ & 0 & $0 \%$ \\
\hline 15 & 9 & $28.13 \%$ & 20 & $62.50 \%$ & 3 & $9.38 \%$ & 0 & $0 \%$ \\
\hline 16 & 14 & $43.75 \%$ & 18 & $56.25 \%$ & 2 & $6.25 \%$ & 3 & $9.38 \%$ \\
\hline 17 & 23 & $71.88 \%$ & 4 & $12.50 \%$ & 5 & $15.63 \%$ & 0 & $0 \%$ \\
\hline
\end{tabular}

No.1, 8, 16 are questions for more choices, so the answer number is over 32 .

Table 2. Statistics of the views on FLES by the 32 parents ( 15 closed questions)

\begin{tabular}{|l|l|l|l|l|l|l|l|l|}
\hline Number & A & Percent & B & Percent & C & Percent & D & Percent \\
\hline 1 & 3 & $9.38 \%$ & 19 & $59.38 \%$ & 10 & $31.25 \%$ & 0 & $0 \%$ \\
\hline 2 & 30 & $93.75 \%$ & 1 & $3.13 \%$ & 1 & $3.13 \%$ & 0 & $0 \%$ \\
\hline 3 & 16 & $50 \%$ & 12 & $37.50 \%$ & 12 & $37.50 \%$ & 2 & $6.25 \%$ \\
\hline 4 & 1 & $3.13 \%$ & 6 & $18.75 \%$ & 5 & $15.63 \%$ & 20 & $62.50 \%$ \\
\hline 5 & 22 & $68.75 \%$ & 1 & $3.13 \%$ & 4 & $12.50 \%$ & 5 & $15.63 \%$ \\
\hline 6 & 9 & $28.13 \%$ & 2 & $6.25 \%$ & 13 & $40.63 \%$ & 8 & $25 \%$ \\
\hline 7 & 23 & $71.88 \%$ & 1 & $3.13 \%$ & 8 & $25 \%$ & 0 & $0 \%$ \\
\hline 10 & 12 & $37.50 \%$ & 6 & $18.75 \%$ & 14 & $43.75 \%$ & 3 & $9.38 \%$ \\
\hline 11 & 4 & $12.50 \%$ & 6 & $18.75 \%$ & 9 & $28.13 \%$ & 13 & $40.63 \%$ \\
\hline 12 & 3 & $9.38 \%$ & 6 & $18.75 \%$ & 5 & $15.63 \%$ & 18 & $56.25 \%$ \\
\hline 14 & 11 & $34.38 \%$ & 17 & $53.13 \%$ & 1 & $3.13 \%$ & 3 & $9.38 \%$ \\
\hline 16 & 20 & $62.50 \%$ & 9 & $28.13 \%$ & 3 & $9.38 \%$ & 0 & $0 \%$ \\
\hline 17 & 5 & $15.63 \%$ & 8 & $25 \%$ & 8 & $25 \%$ & 11 & $34.38 \%$ \\
\hline 18 & 23 & $71.88 \%$ & 5 & $15.63 \%$ & 5 & $15.63 \%$ & 2 & $6.25 \%$ \\
\hline
\end{tabular}

No.3, 9, 17, 18 are questions for more choices, so the answer number is over 32 . 
Table 3. Statistics of the views on FLES by the 31 teachers ( 24 closed questions)

\begin{tabular}{|l|l|l|l|l|l|l|l|l|}
\hline Number & A & Percent & B & Percent & C & Percent & D & Percent \\
\hline 2 & 8 & $25.81 \%$ & 20 & $64.52 \%$ & 2 & $6.45 \%$ & 1 & $3.23 \%$ \\
\hline 4 & 18 & $58.06 \%$ & 13 & $41.94 \%$ & 0 & $0 \%$ & 0 & $0 \%$ \\
\hline 6 & 21 & $67.74 \%$ & 6 & $19.35 \%$ & 1 & $3.23 \%$ & 5 & $16.13 \%$ \\
\hline 7 & 18 & $58.06 \%$ & 0 & $0 \%$ & 15 & $48.39 \%$ & 7 & $22.58 \%$ \\
\hline 8 & 17 & $54.84 \%$ & 10 & $32.26 \%$ & 5 & $16.13 \%$ & 0 & $0 \%$ \\
\hline 11 & 0 & $0 \%$ & 23 & $74.19 \%$ & 4 & $12.90 \%$ & 4 & $12.90 \%$ \\
\hline 13 & 10 & $32.26 \%$ & 21 & $67.74 \%$ & 0 & $0 \%$ & 0 & $0 \%$ \\
\hline 15 & 11 & $35.48 \%$ & 20 & $64.52 \%$ & 0 & $0 \%$ & 0 & $0 \%$ \\
\hline 17 & 29 & $93.55 \%$ & 2 & $6.45 \%$ & 0 & $0 \%$ & 0 & $0 \%$ \\
\hline 19 & 11 & $35.48 \%$ & 15 & $48.39 \%$ & 7 & $22.58 \%$ & 4 & $12.90 \%$ \\
\hline 20 & 19 & $61.29 \%$ & 1 & $3.23 \%$ & 4 & $12.90 \%$ & 8 & $25.81 \%$ \\
\hline 21 & 11 & $35.48 \%$ & 1 & $3.23 \%$ & 16 & $51.61 \%$ & 8 & $25.81 \%$ \\
\hline 22 & 24 & $77.42 \%$ & 1 & $3.23 \%$ & 1 & $3.23 \%$ & 20 & $64.52 \%$ \\
\hline 23 & 23 & $74.19 \%$ & 4 & $12.90 \%$ & 0 & $0 \%$ & 4 & $12.90 \%$ \\
\hline 24 & 4 & $12.90 \%$ & 8 & $25.81 \%$ & 5 & $16.13 \%$ & 14 & $45.16 \%$ \\
\hline 25 & 21 & $67.74 \%$ & 17 & $54.84 \%$ & 5 & $16.13 \%$ & 1 & $3.23 \%$ \\
\hline 26 & 26 & $83.87 \%$ & 0 & $0 \%$ & 4 & $12.90 \%$ & 1 & $3.23 \%$ \\
\hline 27 & 20 & $87.10 \%$ & 8 & $25.81 \%$ & 1 & $3.23 \%$ & 2 & $6.45 \%$ \\
\hline 28 & 24 & $77.42 \%$ & 2 & $6.45 \%$ & 3 & $9.68 \%$ & 2 & $6.45 \%$ \\
\hline 29 & 5 & $16.13 \%$ & 13 & $41.94 \%$ & 13 & $41.94 \%$ & 0 & $0 \%$ \\
\hline 30 & 31 & $100 \%$ & 3 & $9.68 \%$ & 3 & $9.68 \%$ & 0 & $0 \%$ \\
\hline 32 & 2 & $6.45 \%$ & 29 & $93.55 \%$ & 0 & $0 \%$ & 0 & $0 \%$ \\
\hline 34 & 3 & $9.68 \%$ & 27 & $87.10 \%$ & 1 & $3.23 \%$ & 0 & $0 \%$ \\
\hline 36 & 16 & $51.61 \%$ & 14 & $45.16 \%$ & 0 & $0 \%$ & 1 & $3.23 \%$ \\
\hline
\end{tabular}

No.6, 7, 19, 22, 25 and 30 are questions for more choices, so the answer number is over 31 .

Table 4. Average scores of the students in junior 1-3 (Total Score: 150)

\begin{tabular}{|l|l|l|l|l|l|}
\hline No. of Ss & $A v . S c o$. & Tot.Sum & $\bullet$ No. of Ss & $A v . S c o$. & Tot.Sum \\
\hline Jr.1A. (374Ss.) & 130.49 & 48803 & Jr.1A. (47Ss.) & 139.7 & 6567 \\
\hline Jr.1B. (383Ss.) & 129.80 & 49712 & Jr.1B. (46Ss.) & 136.1 & 6260 \\
\hline Jr.2A. (384Ss.) & 119.11 & 45738 & Jr.2A. (47Ss.) & 123.3 & 5795 \\
\hline Jr.2B. (446Ss.) & 114.87 & 42845 & Jr.2B. (46Ss.) & 117.2 & 5392 \\
\hline Jr.3A. (372Ss.) & 110.44 & 41082 & Jr.3A. (46Ss.) & 109.3 & 5027 \\
\hline Jr.3B. (386Ss.) & 97.97 & 37817 & Jr.3B. (47Ss.) & 93.6 & 4401 \\
\hline Jr.3C. (387Ss.) & 96.86 & 37485 & Jr.3C. (46Ss.) & 102.8 & 4727 \\
\hline Av. (390Ss.) & 114.22 & 43355 & Av. (46Ss.) & 117.43 & 5453 \\
\hline
\end{tabular}

Jr.1A. (374Ss.) stands for 374 students in the first semester of Junior One, while Jr.1B. (46Ss.) refers to 46 students in the second semester of Junior One, and the rest can be inferred.

Av. (390Ss.): 390 students on average (who only began to learn English from Junior One);

Av. (46Ss.): 46 students on average (who had learned English for 3 years in elementary school);

Av.Sco.: Average Score; Tot.Sum: Total Sum; No.of Ss: Number of Students;

Table 5. Average scores of the students in senior 1-2 (Total Score: 150)

\begin{tabular}{|l|l|l|l|l|l|}
\hline No. of Ss & $A v . S c o$ & Tot.Sum & $\bullet$ No. of Ss & $A v . S c o$ & Tot.Sum \\
\hline Sr.1A. (447Ss.) & 70.87 & 31681 & Sr.1A. (34Ss.) & 66.44 & 2259 \\
\hline Sr.1B. (454Ss.) & 77.20 & 35048 & Sr.1B. (33Ss.) & 75.67 & 2497 \\
\hline Sr.2A. (445Ss.) & 86.95 & 38692 & Sr.2A. (33Ss.) & 83.18 & 2745 \\
\hline Sr.2B. (446Ss.) & 80.69 & 35989 & Sr.2B. (32Ss.) & 82.53 & 2641 \\
\hline Av. (448Ss.) & 78.93 & 35353 & Av. (33Ss.) & 76.96 & 2546 \\
\hline
\end{tabular}

Sr. stands for senior students, and the rest can be inferred as in Table 4. 
Table 6. Descriptive statistics of the scores of junior 1-3 and senior 1-2 (Total Score: 150)

\begin{tabular}{|c|c|c|c|c|c|c|}
\hline & $\mathrm{N}$ & Minimum & Maximum & Mean & Std. Deviation & Variance \\
\hline & Statistic & Statistic & Statistic & Statistic & Statistic & Statistic \\
\hline Jr. Av. 390Ss. & 7 & 96.86 & 130.49 & 114.2200 & 13.61068 & 185.251 \\
\hline Jr. Av. 46Ss. & 7 & 93.60 & 139.70 & 117.4286 & 16.96582 & 287.839 \\
\hline Sr. Av. 448Ss & 4 & 70.87 & 86.95 & 78.9275 & 6.71750 & 45.125 \\
\hline Sr. Av. 33Ss. & 4 & 66.44 & 83.18 & 76.9550 & 7.78990 & 60.683 \\
\hline Valid N (listwise) & 4 & & & & & \\
\hline
\end{tabular}

Table 7. Paired samples statistics on the scores of junior 1-3\& senior 1-2 (Total Score: 150)

Paired Samples Statistics

\begin{tabular}{|c|c|c|c|c|c|}
\hline & & Mean & N & Std. Deviation & Std. Error Mean \\
\hline Pair 1 & Jr. Av. 390Ss. & 114.2200 & 7 & 13.61068 & 5.14436 \\
\hline & Jr. Av. 46Ss. & 117.4286 & 7 & 16.96582 & 6.41248 \\
\hline Pair 2 & Sr. Av. 448Ss. & 78.9275 & 4 & 6.71750 & 3.35875 \\
\hline & Sr. Av. 33Ss. & 76.9550 & 4 & 7.78990 & 3.89495 \\
\hline
\end{tabular}

Table 8. Paired samples correlations on the scores of junior 1-3\& senior 1-2 (Total Score: 150)

Paired Samples Correlations

\begin{tabular}{|c|c|c|c|c|}
\hline & & $\mathrm{N}$ & Correlation & Sig. \\
\hline Pair 1 & Jr. Av. 390Ss.\& Jr. Av. 46Ss. & 7 & $.977^{* *}$ & .000 \\
\hline Pair 2 & Sr. Av. 448Ss.\& Sr. Av. 33Ss. & 4 & .935 & .065 \\
\hline
\end{tabular}

** Correlation is significant at the 0.01 level (2-tailed).

Table 9. Paired samples test on the scores of junior 1-3\& senior 1-2 (Total Score: 150)

Paired Samples Test

\begin{tabular}{|c|c|c|c|c|c|c|c|c|c|}
\hline & & \multicolumn{5}{|c|}{ Paired Differences } & \multirow[t]{3}{*}{$\mathrm{t}$} & \multirow[t]{3}{*}{ df } & \multirow{3}{*}{$\begin{array}{c}\text { Sig. } \\
\text { (2-tailed) }\end{array}$} \\
\hline & & \multirow[t]{2}{*}{ Mean } & \multirow[t]{2}{*}{\begin{tabular}{|c|} 
Std. \\
Deviation
\end{tabular}} & \multirow[t]{2}{*}{$\begin{array}{l}\text { Std. Error } \\
\text { Mean }\end{array}$} & \multicolumn{2}{|c|}{$\begin{array}{l}\text { 95\% Confidence Interval of the } \\
\text { Difference }\end{array}$} & & & \\
\hline & & & & & Lower & Upper & & & \\
\hline $\begin{array}{c}\text { Pair } \\
1 \\
\end{array}$ & $\begin{array}{c}\text { Jr.Av.390Ss. \& } \\
\text { Jr. Av. 46Ss } \\
\end{array}$ & -3.2086 & 4.67466 & 1.76686 & -7.5319 & 1.1148 & -1.816 & 6 & .119 \\
\hline $\begin{array}{c}\text { Pair } \\
2\end{array}$ & \begin{tabular}{|c|} 
Sr. Av. 448Ss.\& Sr. Av. \\
33Ss.
\end{tabular} & 1.9725 & 2.82850 & 1.41425 & -2.5283 & 6.4733 & 1.395 & 3 & .257 \\
\hline
\end{tabular}

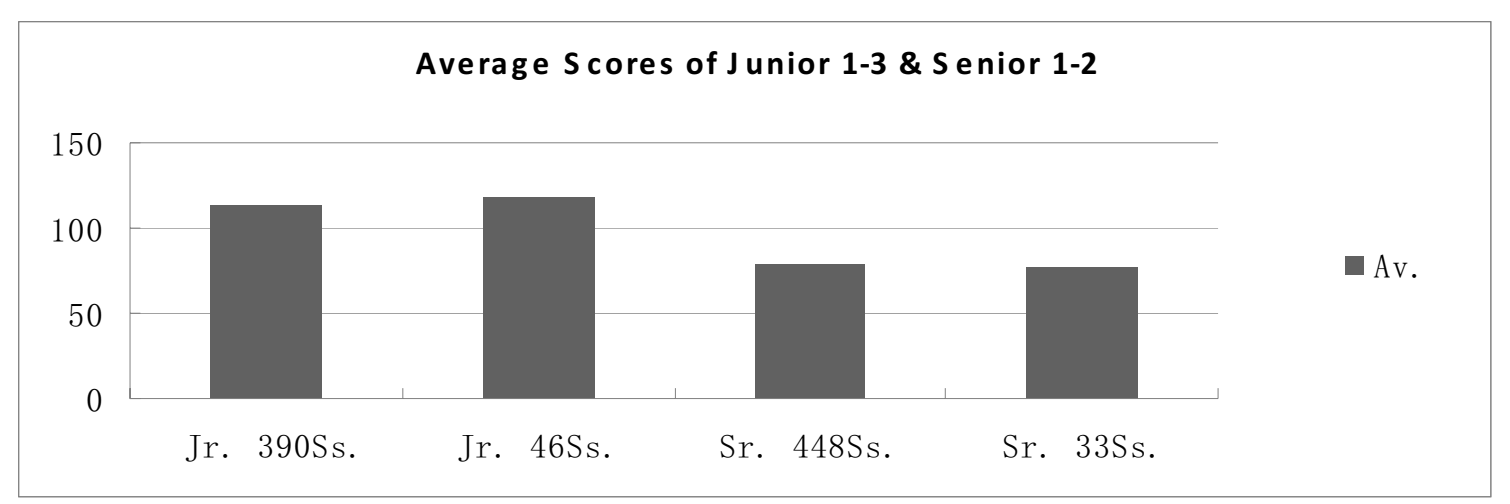

Figure 1. Average Scores of Junior 1-3 \& Senior 1-2 